\title{
Serum Progesterone Levels as Predictor of Outcome in Severe Traumatic Brain Injury: Analysis of Cohort of 100 Patients
}

\author{
Sarbjit Singh Chhiber ${ }^{1} \quad$ Adfer Gul ${ }^{2}$ Sajad Arif ${ }^{1} \quad$ Abrar Ahad Wani ${ }^{1} \quad$ Altaf Umar Ramzan ${ }^{1}$ \\ ${ }^{1}$ Department of Neurosurgery, Sher-e-Kashmir Institute of Medical \\ Sciences, Soura, Srinagar, Jammu and Kashmir, India \\ ${ }^{2}$ Department of Plastic Surgery, Sher-e-Kashmir Institute of Medical \\ Sciences, Soura, Srinagar, Jammu and Kashmir, India \\ Address for correspondence Sarbjit Singh Chhiber, MCh, \\ Department of Neurosurgery, Shere-Kashmir Institute of Medical \\ Sciences, Soura, Srinagar, Jammu and Kashmir 190011, India \\ (e-mail: sarabjitchhiber@gmail.com).
}

Indian J Neurosurg 2021;10:230-235.

\begin{abstract}
Keywords

- severe traumatic brain injury

- progesterone

- biochemical marker

- outcome

Despite advances in research and improved neurological intensive care in recent years, the clinical outcome of severely head injured patients is still poor. Primary insult is followed by a complex cascade of molecular and biochemical events that lead to neuroinflammation, brain edema, and delayed neuronal death. No specific pharmacological therapy is currently available which prevents the development of secondary brain injuries, and most therapeutic strategies have failed in translation from bench to bedside. There are limitations of clinical and radiological methods in delineating the exact severity and prognosis of traumatic brain injury (TBI). A myriad complex biochemical markers are under investigation to delineate the extent of brain tissue damage and to independently predict the outcome, but a search for simple biomarker still eludes the research. Progesterone, a gonadal hormone and a neurosteroid, although controversial as a neuroprotective agent, may hold promise as a simple biochemical marker of the outcome in severe TBI.
\end{abstract}

\section{Introduction}

Traumatic brain injury (TBI) is one of the leading causes of injury-related death and severe disability worldwide, resulting in large direct and indirect costs to society. The management of TBI currently includes preventing further neurological insults, managing the intracranial pressure (ICP), and surgical procedures. ${ }^{1}$ Despite advances in research and improved neurological intensive care in recent years, the clinical outcome of severely head injured patients is still poor. Evaluation of direct and indirect costs reveals that TBI is a 60 billion dollar "industry" in the United States. ${ }^{2-5}$ In contrast to the primary insult, secondary brain injury evolves over time. These are characterized by a complex cascade of molecular and biochemical events that lead to neuroinflammation, brain edema, and delayed neuronal death. ${ }^{6}$ Apart from the evidence-based guidelines for treatment of TBI published by Brain Trauma Foundation, ${ }^{7}$ no specific pharmacological therapy is currently available which prevents the development of secondary brain injuries, and most therapeutic strategies have failed in translation from "bench to bedside". ${ }^{8}$ The recent disappointing results of the Progesterone for the Treatment of Traumatic Brain Injury (ProTECT) and Study of a Neuroprotective Agent, Progesterone, in Severe Traumatic Brain Injury (SyNAPSe) phase III trials for progesterone in TBI is one example of such failed translation from bench to bedside. ${ }^{9}$ Progesterone showed considerable efficacy as a neuroprotective agent in the treatment of TBI in animal studies $^{10-14}$ and two moderately encouraging phase II clinical reports, but two similarly designed phase III TBI clinical published online March 25, 2021
DOI https://doi.org/

$10.1055 / \mathrm{s}-0041-1726610$ ISSN 2277-954X (c) 2021. Neurological Surgeons' Society of India.

This is an open access article published by Thieme under the terms of the Creative Commons Attribution-NonDerivative-NonCommercial-License, permitting copying and reproduction so long as the original work is given appropriate credit. Contents may not be used for commercial purposes, or adapted, remixed, transformed or built upon. (https://creativecommons.org/licenses/by-nc-nd/4.0/).

Thieme Medical and Scientific Publishers Pvt. Ltd. A-12, 2nd Floor, Sector 2, Noida-201301 UP, India 
trials recently resulted in negative outcomes. ${ }^{15-18}$ Pending the validation of the role of progesterone in ameliorating the secondary injury in TBI, two recent prospective studies have concluded that serum progesterone levels may have a role as biochemical marker to independently predict the global outcome in cases of TBI. ${ }^{19,20}$ We conducted a prospective observational study of a cohort of 100 patients with severe TBI (Glasgow coma scale [GCS] score $\leq 8$ at arrival) and analyzed the predictive value of this biomarker (serum progesterone) on two validated and dichotomized measures of outcome: Glasgow outcome scale (GOS) score and functional independence measure (FIM). We found that admission serum progesterone levels significantly ( $p$ value $\leq 0.05$ ) predicted the outcome on dichotomized (favorable vs. unfavorable, dependent vs. independent) measures of outcome at 3 months.

\section{Materials and Methods}

\section{Study Design}

We conducted a prospective observational statistician blinded outcome assessor study on a cohort of patients who had suffered severe TBI at the time of admission to SKIMS, which is the tertiary care center for the management of TBI in the region of J\&K. The cohort included all the eligible patients of severe TBI presented to the Dept. of Neurosurgery SKIMS between November 2013 to November 2015.

\section{Eligibility}

A total of 100 male and female patients between 16 and 70 years of age presenting within 12 hours of suffering closed head injury with GCS score of 4 to 8 (on a scale from 3 to 15), assessed after resuscitation, a TBI diagnosed by history and examination, visible pathologic changes consistent with TBI as assessed on the admission CT scan, and at least one reactive pupil were included in the study. Patients were excluded if they were less than 16 years or greater than 70 years of age, had a GCS score of 3, bilaterally fixed and dilated pupils, a life expectancy of less than 24 hours, prolonged or uncorrectable hypoxemia (partial pressure of arterial oxygen, $<60 \mathrm{~mm} \mathrm{Hg}$ ), hypotension (systolic blood pressure, $<90 \mathrm{~mm} \mathrm{Hg}$ ) at the time of admission, spinal cord injury, pregnant and lactating females, only an isolated epidural hematoma, or coma that was suspected to be due primarily to other causes or comorbid illnesses like diabetes mellitus, ischemic heart disease or known malignancy.

\section{Study Procedure}

Peripheral blood $(\neq 2.5 \mathrm{~mL}$ ) was collected from the sample drawn at the time of presentation for general investigations in sterile serum collection tubes and allowed to clot. The tubes were then subjected to centrifugation at $2500 \mathrm{rpm}$ for 5 minutes to separate the serum. The serum was aspirated and poured in $1.5 \mathrm{~mL}$ microfuge tubes after proper labeling and stored at $-20^{\circ} \mathrm{C}$, which were then subjected to the enzyme-linked immunosorbent assay (ELISA) technique for estimation of serum progesterone levels.

General treatment and the treatment of raised ICP were in accordance with published international guidelines. ${ }^{7}$

\section{Outcome Measures}

GOS score was used as the measure of primary outcome. The scale has five levels: 1 (death), 2 (vegetative state), 3 (severe disability), 4 (moderate disability), and 5 (good recovery). For statistical clarity, the GOS was further dichotomized into favorable outcome (GOS 4 and 5) and unfavorable outcome (GOS 1, 2 and 3).

The FIM scale was used as secondary measure of outcome which assesses physical and cognitive disability. FIM is scored from 1 to 7 based on level of independence: 7 complete independence-fully independent; 6 modified independence-requiring the use of a device but no physical help; 5 supervision-requiring only standby assistance or verbal prompting or help with set-up; 4 minimal assistance-requiring incidental hands-on help only (subject performs $>75 \%$ of the task); 3 moderate assistance-subject still performs 50 to $75 \%$ of the task; 2 maximal assistance-subject provides less than half of the effort (25-49\%); 1 total assistance-subject contributes $<25 \%$ of the effort or is unable to do the task.

For statistical clarity, the FIM scale was further dichotomized into independent outcome (FIM scale of 6 and 7) and dependent outcome (FIM scale of 1-5).

\section{Statistical Analysis}

The baseline parameters, serum progesterone levels, and outcome are presented as either number/percentage, mean ( \pm standard deviation $[S D]$ ), or median (interquartile [IQR]), wherever appropriate. Statistical analysis of serum progesterone level and dichotomized outcome was performed using the $t$-test considering $p<0.005$ to be significant.

\section{Ethical Considerations}

The blood samples were drawn as a part of general investigations on arrival to emergency department, with $2.5 \mathrm{~mL}$ saved for the study. The study was a prospective observational study, so there were no ethical issues related to the study.

\section{Results}

\section{Demographic Profile}

A total of 100 patients suffering from severe TBI (GCS score 4-8) with a mean age of $41.20 \pm 16.20$ years mean, and GCS score of $6.48 \pm 1.61$ at admission were analyzed. The demographic profile of the study is shown in - Table 1.

\section{Analysis of Outcome}

The GOS score of the study cohort at 3 months is shown in - Table 2. The favorable outcome is seen in 60 of the 100 patients, whereas only 40 had an unfavorable outcome. The mean serum progesterone levels were $2.48 \pm 1.97 \mathrm{ng} / \mathrm{mL}$. The dichotomized GOS score ( - Table 3 ) showed a mean serum progesterone level of $7.55 \pm 2.55 \mathrm{ng} / \mathrm{mL}$ in favorable outcome group (GOS 4-5) and a mean level of $2.58 \pm 1.04$ in unfavorable outcome group (GOS1-3). On statistical analysis, we found that the difference of mean serum progesterone level was significantly different between the two groups $(p<0.0001)$, thus predicting a favorable outcome (GOS 4-5) 
Table 1 Demographic profile $(n=100)$

\begin{tabular}{|c|c|}
\hline Age (16-70 years) & \\
\hline Mean \pm SD & $41.20 \pm 16.20$ \\
\hline IQR & 29 \\
\hline Sex (male) & $90(90)$ \\
\hline \multicolumn{2}{|l|}{ Cause of injury (\%) } \\
\hline Road traffic accidents & 58 \\
\hline Falls & 32 \\
\hline Assaults & 10 \\
\hline Average time since injury (min) & $\begin{array}{l}151.90 \pm 86.43 \text { (range: } \\
15-420 \mathrm{~min} \text { ) }\end{array}$ \\
\hline \multicolumn{2}{|l|}{ GCS score at admission } \\
\hline Mean $\pm Y$ & $6.48 \pm 1.61$ \\
\hline IQR & 3 \\
\hline Polytrauma (\%) & 53 \\
\hline \multicolumn{2}{|l|}{ CT findings } \\
\hline Contusions & 54 \\
\hline Acute subdural hematoma & 30 \\
\hline Fractures & 25 \\
\hline $\mathrm{SAH}$ & 20 \\
\hline DAl & 5 \\
\hline Extradural hematoma & 5 \\
\hline Decompressive craniectomy (\%) & $48(48)$ \\
\hline Length of hospital stay (days) & $\begin{array}{l}7.96 \pm 7.01 \text { (range: } \\
1-32 \text { days) }\end{array}$ \\
\hline $\begin{array}{l}\text { Mortality rate at } 3 \text { months } \\
(n=100)\end{array}$ & $30 \%$ \\
\hline
\end{tabular}

Abbreviations: DAI, diffuse axonal injury; GCS, Glasgow coma scale; IQR, interquartile range; $\mathrm{SAH}$, subarachnoid hemorrhage.

Table 2 GOS score at 3 months

\begin{tabular}{|l|l|l|}
\hline $\begin{array}{l}\text { GOS } \\
\text { score }\end{array}$ & $\begin{array}{l}\text { No. of patients } \\
(n=100)\end{array}$ & $\begin{array}{l}\text { Serum progesterone } \\
\text { levels } \\
\text { Mean } \pm \text { SD }(\mathrm{ng} / \mathrm{mL})\end{array}$ \\
\hline 1 & 30 & $0.78 \pm 0.50$ \\
\hline 3 & 10 & $1.99 \pm 0.23$ \\
\hline 4 & 32 & $2.95 \pm 2.08$ \\
\hline 5 & 28 & $3.93 \pm 1.80$ \\
\hline Total & 100 & $2.48 \pm 1.97$ \\
\hline
\end{tabular}

Abbreviation: GOS Glasgow outcome scale,.

at 3 months in patients with higher mean serum progesterone levels at admission.

The FIM score of the study cohort at 3 months is shown in - Table 4. The independent outcome is seen in 42 of the 70 patients, whereas only 28 had an unfavorable outcome. The mean serum progesterone levels were $3.2 \pm 1.91 \mathrm{ng} / \mathrm{mL}$. The dichotomized FIM score ( - Table 5 ) showed a mean serum progesterone level of $3.81 \pm 2.27 \mathrm{ng} / \mathrm{mL}$ in independent outcome group (FIM 6-7) and a mean level of $1.51 \pm 0.88 \mathrm{ng} / \mathrm{mL}$ in dependent outcome group (FIM 1-5). On statistical analysis,
Table 3 Dichotomized GOS score at 3 months versus serum progesterone levels

\begin{tabular}{|l|l|l|l|}
\hline $\begin{array}{l}\text { GOS score } \\
(n=100)\end{array}$ & $\begin{array}{l}\text { No. of } \\
\text { patients }\end{array}$ & $\begin{array}{l}\text { Serum } \\
\text { progesterone } \\
\text { levels } \\
\text { Mean } \pm \text { SD } \\
(\mathrm{ng} / \mathrm{mL})\end{array}$ & -Value \\
\cline { 1 - 3 } Favorable $^{4,5}$ & $60(60 \%)$ & $7.88 \pm 2.55$ & 0.000 \\
\cline { 1 - 2 } Unfavorable $^{1-3}$ & $40(40 \%)$ & $2.58 \pm 1.04$ & \\
\hline
\end{tabular}

Abbreviation: GOS, Glasgow outcome scale.

Table 4 FIM score at 3 months

\begin{tabular}{|l|l|l|}
\hline Score & $\begin{array}{l}\text { No. of patients } \\
(\boldsymbol{n}=\mathbf{7 0})\end{array}$ & $\begin{array}{l}\text { Serum progesterone } \\
\text { levels Mean } \pm \text { SD }(\mathrm{ng} / \mathrm{mL})\end{array}$ \\
\hline 2 & 1 & 1.60 \\
\hline 3 & 3 & $1.89 \pm 0.20$ \\
\hline 4 & 10 & $2.1 \pm 0.25$ \\
\hline 5 & 14 & $2.6 \pm 0.26$ \\
\hline 6 & 22 & $4.4 \pm 2.95$ \\
\hline 7 & 20 & $3.2 \pm 0.92$ \\
\hline
\end{tabular}

Abbreviation: FIM, functional independence measure.

Table 5 Dichotomized FIM score at 3 months versus serum progesterone levels

\begin{tabular}{|l|l|l|l|}
\hline $\begin{array}{l}\text { FIM score } \\
(\boldsymbol{n}=70)\end{array}$ & $\begin{array}{l}\text { No. of } \\
\text { patients }\end{array}$ & $\begin{array}{l}\text { Serum } \\
\text { progesterone } \\
\text { levels } \\
\text { Mean } \pm \text { SD } \\
(\mathrm{ng} / \mathrm{mL})\end{array}$ & -Value \\
\cline { 1 - 3 } Independent $^{6,7}$ & $42(60 \%)$ & $3.81 \pm 2.27$ & $<0.001$ \\
\cline { 1 - 3 } Dependent $^{1-5}$ & $28(40 \%)$ & $1.51 \pm 0.88$ & \\
\hline
\end{tabular}

Abbreviation: FIM, functional independence measure.

we found that the difference of mean serum progesterone level was significantly different between the two groups $(p<0.001)$, thus predicting functionally an independent outcome (FIM 6-7) at 3 months in patients with higher mean serum progesterone levels at admission.

Note was also made that none of the patients with serum progesterone levels less than $1 \mathrm{ng} / \mathrm{mL}(n=20)$ at admission survived.

\section{Discussion}

TBI is one of the leading causes of injury-related death and severe disability worldwide, resulting in large direct and indirect costs to society. ${ }^{1}$ Apart from primary injury, the secondary brain injury is the result of complex interplay of brain tissue-specific antigens, hormonal imbalances, and cytokine-mediated humoral and cellular immune reactions, ${ }^{21-23}$ eventually leading to a complex cascade of molecular and biochemical events that lead to neuroinflammation, brain edema, and delayed neuronal death, adding 
to the quantum of severity of brain tissue damage. ${ }^{24}$ Due to limitations of clinical and radiological methods in delineating the exact severity and prognosis of TBI, there has been a considerable paradigm shift toward the development and use of biochemical markers to delineate the extent of brain tissue damage and to independently predict the outcome. ${ }^{19}$

Dhandapani et al found that unfavorable neurological outcome at 6 months was associated with 15\% fall of serum albumin or low urinary creatinine at 3 weeks. ${ }^{25}$ Takahashi et al identified fibrinolytic parameters, $\alpha_{2}$-plasmin inhibitor-plasmin complex (PIC) levels, and D-dimer levels as admission prognostic markers of head injury in patients and found that higher levels predicted worse prognosis. ${ }^{26}$ Specific brain-tissue antigens like $\mathrm{S} 100-\mathrm{B},{ }^{27}$ neuron-specific enolase (NSE), ${ }^{28,29}$ and glial fibrillary acidic protein (GFAP), have been studied extensively over the past decade in various laboratory and clinical studies as potential markers of severity of brain injury. Similarly, the role of proinflammatory (interleukin [IL]-6, IL-1, tumor necrosis factor-a [TNF-a]) and anti-inflammatory (IL-4, IL-10, transforming growth factor) cytokines have been studied in recent trials. ${ }^{30-32}$ Many of these markers either have a very short half-life, have issue of specific window period, serum levels are affected by other confounding factors like sepsis, hypo-perfusion, liver damage, etc., have poor blood brain penetration requiring cerebrospinal fluid (CSF) sampling, or studies have shown ambiguous results. ${ }^{19} \mathrm{~A}$ recent study by Raheja et al concluded that out of NSE, GFAP, S100-B, TNF $\alpha$ and IL 6, only serum GFAP and IL6 levels at day 7 of injury could significantly predict long-term outcome in severe TBI at 1 year.

Recently, prospective studies have concluded that serum progesterone levels may have a role as biochemical marker to independently predict the global outcome in cases of TBI. Progesterone, a gonadal hormone and neurosteroid naturally distributed in human brains, has potent neuroprotective properties. ${ }^{8}$ Progesterone is produced by the ovaries and the placenta and predominantly considered as female hormone. In the brains of both sexes, progesterone synthesized by oligodendrocytes and some neurons plays an important role in neuronal development during gestation. ${ }^{33,34}$ Progesterone receptors are widely expressed in the developing and adult brain, so various brain regions are the normal targets of progesterone. ${ }^{35}$ Indeed, the 10 -fold increase in progesterone synthesis during fetal growth is considered an evolutionary mechanism of progesterone to protect the fetus during gestation. Because many processes involved in CNS repair after brain injury are thought to recapitulate what occurs during normal brain development, ${ }^{36}$ progesterone may be actively involved in TBI recovery and thus involved in neuroprotection. ${ }^{8}$ Progesterone is thought to mediate its neuroprotective effects by reducing cerebral edema, lipid peroxidation, isoprostanes, and expression of proinflammatory genes; generating metabolites that reduce proapoptotic and increase antiapoptotic enzymes; and modifying the expression of vascular endothelial growth factor, brain-derived neurotrophic growth factor, and aquaporins responsible for development of edema. ${ }^{37}$ In literature, more than 200 articles have reported the neuroprotective effects of progesterone in four species, including humans, and in 22 different injury models, including TBI, stroke, spinal cord injury and neurodegenerative disorders. ${ }^{24}$ Also two phase II clinical reports from a level 1 trauma centers in Atlanta USA in 2001 and Hangzhou, China, in 2004, respectively showed encouraging results for progesterone as a neuroprotective agent in TBI. ${ }^{17,18}$ In contrast, recently two similarly designed phase III TBI clinical trials failed to demonstrate any positive effect of progesterone as a neuroprotective agent on outcomes. ${ }^{15,16}$ It also triggered considerable speculation about the reasons for the negative outcomes of these two studies in particular and for those of all previous phase II TBI clinical trials in general. ${ }^{9}$

Despite contradictory results of progesterone as a neuroprotective agent, two reports ${ }^{19,20}$ have shed light on value of serum progesterone at admission in predicting the outcome of TBI patients. Our study also showed a very significant role of serum progesterone levels as a biomarker of outcome on outcomes in TBI patients.

Dasgupta et $\mathrm{al}^{20}$ in a prospective observational study of 100 male patients sought to investigate whether lower levels of baseline serum progesterone at admission within 10 hours of injury can be used to predict worse outcome in severe-to-moderate TBI patients (GCS 4-12), as measured by GOS and Functional FIM scores at 30 days postinjury. Mean age was $35 \pm 11.4$ years, average time taken to reach the hospital was $3.14 \pm 1.8$ hours, and index GCS score was 4 to 8 in 84 patients and 9 to 12 in 16 patients. The mean progesterone level in the group with poor outcome (GOS 1-3) was 0.89 $\pm 033 \mathrm{ng} / \mathrm{mL}$ and the mean progesterone level in the group with good outcome (GOS 4-5) was $1.03 \pm 0.18 \mathrm{ng} / \mathrm{mL}$. Despite the mean serum progesterone levels being higher in patients with good outcome (GOS 4-5), they did not find this difference statistically significant ( $p$ value 0.16 ). In contrast, when the FIM score was analyzed, the mean progesterone level in the group with poor outcome (FIM 1-4) was $0.9 \pm 0.45 \mathrm{ng} / \mathrm{mL}$ and the mean progesterone level in the group with good outcome (FIM 5-7) was $1.27 \pm 0.32 \mathrm{ng} / \mathrm{mL}$, which was a statistically significant difference ( $p$ value 0.048 ). So, their findings suggested potential application of serum progesterone levels as an admission prognostic marker in moderate-to-severe male TBI patients.

Our study had female patients (10\%) as well and included only patients who had suffered severe TBI (GCS 4-8). We used GOS score as a measure of global outcome (favorable vs. unfavorable) and FIM score as measure of functional outcome (independent vs. dependent) and found highly significant difference in the mean serum progesterone levels for both measures of outcome respectively whereas Dasgupta et $\mathrm{al}^{20}$ used good and poor outcomes for both measures. We think that since Dasgupta et $\mathrm{al}^{20}$ included patients with moderate TBI (GCS 9-12), and this might be responsible for not getting statistically significant results for the measure of GOS scale for outcome, as moderate TBI is a distinct entity. Similar to their results, we also made note of extremely poor outcome (GOS 1) for patients with serum progesterone levels less than $1 \mathrm{ng} / \mathrm{mL}$.

Raheja et $\mathrm{al}^{19}$ analyzed 86 patients ( $84.9 \%$ of them male) with severe TBI (GCS 4-8) with mean age 32.3 years as a part 
of a prospective, outcome-assessor, and statistician-blinded, randomized, placebo-controlled phase II trial of progesterone with or without hypothermia. The average ICP measured serially for 5 days was $11.8 \mathrm{~mm} \mathrm{Hg}$. Decompressive craniectomy was performed for refractory intracranial hypertension in $32.6 \%$ of patients. Favorable GOS scores were found in $71.4 \%$ of patients at 6 months and in $78.5 \%$ of patients at 12 months. Also, $63.3 \%$ and $81.5 \%$ of patients were functionally independent at 6 and 12 months, respectively. The mortality rate was $14.3 \%$ and $16.9 \%$ at the 6 - and 12 -month follow-up, respectively. In multivariate logistic regression analysis, they found that day 7 serum progesterone levels were independent predictors of unfavorable outcome at 1 year and admission IL-6 and Day 7 GFAP were independent predictors of favorable outcome at 1 year. They concluded that serial serum progesterone, GFAP, and IL-6 monitoring could aid in prognosticating outcomes in patients with severe TBI. Thus, progesterone had a significant role in predicting long-term favorable outcome. They also suggested whether a cause-and-effect relationship or a mere association of these biomarkers to outcome needs to be further studied for better understanding of the pathophysiology in severe TBI and for choosing potential therapeutic targets.

Our study found admission serum progesterone levels a very significant predictor of favorable global (GOS) as well functional outcomes. In contrast, Raheja et $\mathrm{al}^{19}$ found only day 7 serum progesterone levels to be a significant predictor of favorable outcome. So, whether serial measurements of serum progesterone levels from day 1 to day 7 will give a better picture is only speculative. Another difference was the number of patients who underwent decompressive craniectomy for raised ICP. In our study group, more patients underwent surgical intervention (48\%) as compared with study done by Raheja et al (32.6\%). ${ }^{19}$ The reason could be lack of ICP monitoring in our cohort and depending only on clinical and radiological findings for surgical decisions. Also, hypothermia and therapeutic progesterone administration was used in a good proportion of patients. The same reasons could explain a higher mortality in our patients (30\%). Overall, the results imply the significant role of serum progesterone levels as a predictor of global as well as functional outcome in severe TBI.

We speculate that serum progesterone levels are a reflection of degree of suppression of hypothalamic-pituitary-gonadal axis, the degree of which depends on the severity of trauma, which ultimately influences the outcome.

\section{Conclusion}

Serum progesterone levels have a potential to serve as biomarker of outcome in cases of TBI. Low serum progesterone levels at admission predict bad overall as well as functional outcomes. Whether single measurements (day 1 vs. day 7 ) or serial measurements (day 1 to day 7 ) have better predictive values has to be validated in further larger studies.

Conflict of Interest

None declared.

\section{References}

1 Roberts I, Schierhout G, Alderson P. Absence of evidence for the effectiveness of five interventions routinely used in the intensive care management of severe head injury: a systematic review. J Neurol Neurosurg Psychiatry 1998;65(5):729-733

2 Wrona RM. The use of state workers' compensation administrative data to identify injury scenarios and quantify costs of work-related traumatic brain injuries. J Safety Res 2006;37(1):75-81

3 Davis KL, Joshi AV, Tortella BJ, Candrilli SD. The direct economic burden of blunt and penetrating trauma in a managed care population. J Trauma 2007;62(3):622-629

4 Gamboa AMJ Jr, Holland GH, Tierney JP, Gibson DS. American Community Survey: earnings and employment for persons with traumatic brain injury. NeuroRehabilitation 2006;21(4):327-333

5 Woolhandler S, Himmelstein DU. Double catastrophe: injury-related bankruptcies. Med Care 2007;45(8):699-701

6 Stahel PF, Smith WR, Moore EE. Hypoxia and hypotension, the "lethal duo" in traumatic brain injury: implications for prehospital care. Intensive Care Med 2008;34(3):402-404

7 The Brain TraumaFoundation. Guidelines for the management of severe traumatic brain injury. J Neurotrauma 2007;24:S1-S106

8 Beauchamp K, Mutlak H, Smith WR, Shohami E, Stahel PF. Pharmacology of traumatic brain injury: where is the "golden bullet"? Mol Med 2008;14(11-12):731-740

9 Howard RB, Sayeed I, Stein DG. Suboptimal dosing parameters as possible factors in the negative phase III clinical trials of progesterone for traumatic brain injury. J Neurotrauma 2017;34(11):1915-1918

10 Roof RL, Hoffman SW, Stein DG. Progesterone protects against lipid peroxidation following traumatic brain injury in rats. Mol Chem Neuropathol 1997;31(1):1-11

11 Pettus EH, Wright DW, Stein DG, Hoffman SW. Progesterone treatment inhibits the inflammatory agents that accompany traumatic brain injury. Brain Res 2005;1049(1):112-119

12 Shear DA, Galani R, Hoffman SW,Stein DG. Progesterone protects against necrotic damage and behavioral abnormalities caused by traumatic brain injury. Exp Neurol 2002;178(1):59-67

13 Thomas AJ, Nockels RP, Pan HQ Shaffrey CI, Chopp M. Progesterone is neuroprotective after acute experimental spinal cord trauma in rats. Spine 1999;24(20):2134-2138

14 Wright DW, Bauer ME, Hoffman SW, Stein DG. Serum progesterone levels correlate with decreased cerebral edema after traumatic brain injury in male rats. J Neurotrauma 2001;18(9):901-909

15 Wright DW, Yeatts SD, Silbergleit R, et al. NETT Investigators. Very early administration of progesterone for acute traumatic brain injury. N Engl J Med 2014;371(26):2457-2466

16 Skolnick BE, Maas AI, Narayan RK, et al. SYNAPSE Trial Investigators. A clinical trial of progesterone for severe traumatic brain injury. N Engl J Med 2014;371(26):2467-2476

17 Wright DW, Kellermann AL, Hertzberg VS, et al. ProTECT: a randomized clinical trial of progesterone for acute traumatic brain injury. Ann Emerg Med 2007;49(4):391-402

18 Xiao G, Wei J, Yan W, Wang W, Lu Z. Improved outcomes from the administration of progesterone for patients with acute severe traumatic brain injury: a randomized controlled trial. Crit Care 2008;12(2):R61

19 Raheja A, Sinha S, Samson N, et al. Serum biomarkers as predictors of long-term outcome in severe traumatic brain injury: analysis from a randomized placebo-controlled Phase II clinical trial. J Neurosurg 2016;125(3):631-641

20 Dasgupta A, Sarma D, Saika UK. Serum progesterone as an admission prognostic marker in male traumatic brain injury patients. J Neurol Res 2012;2(2):44-47 
21 Czeiter E, Mondello S, Kovacs N, et al. Brain injury biomarkers may improve the predictive power of the IMPACT outcome calculator. J Neurotrauma 2012;29(9):1770-1778

22 Wagner AK, McCullough EH, Niyonkuru C, et al. Acute serum hormone levels: characterization and prognosis after severe traumatic brain injury. J Neurotrauma 2011;28(6):871-888

23 Woodcock T, Morganti-Kossmann MC. The role of markers of inflammation in traumatic brain injury. Front Neurol 2013;4:18

24 Wei J, Xiao GM. The neuroprotective effects of progesterone on traumatic brain injury: current status and future prospects. Acta Pharmacol Sin 2013;34(12):1485-1490

25 Dhandapani SS, Manju D, Vivekanandhan S, Agarwal M, Mahapatra AK. Prospective longitudinal study of biochemical changes in critically ill patients with severe traumatic brain injury:Factors associated and outcome at 6 months. J Neurotrauma 2010;7:23-27

26 Takahashi H, Urano T, Takada Y, Nagai N, Takada A. Fibrinolytic parameters as an admission prognostic marker of head injury in patients who talk and deteriorate. J Neurosurg 1997;86(5):768-772

27 Vos PE, Jacobs B, Andriessen TM, et al. GFAP and S100B are biomarkers of traumatic brain injury: an observational cohort study. Neurology 2010;75(20):1786-1793

28 Diaz-Arrastia R, Wang KK, Papa L, et al. TRACK-TBI Investigators. Acute biomarkers of traumatic brain injury: relationship between plasma levels of ubiquitin C-terminal hydrolase-L1 and glial fibrillary acidic protein. J Neurotrauma 2014;31(1):19-25
29 Guzel A, Er U, Tatli M, et al. Serum neuron-specific enolase as a predictor of short-term outcome and its correlation with Glasgow Coma Scale in traumatic brain injury. Neurosurg Rev 2008;31(4):439-444

30 Chiaretti A, Antonelli A, Mastrangelo A, et al. Interleukin-6 and nerve growth factor upregulation correlates with improved outcome in children with severe traumatic brain injury. J Neurotrauma 2008;25(3):225-234

31 Ferreira LC, Regner A, Miotto KD, et al. Increased levels of interleukin-6, -8 and -10 are associated with fatal outcome following severe traumatic brain injury. Brain Inj 2014;28(10):1311-1316

32 Lenzlinger PM, Morganti-Kossmann MC, Laurer HL, McIntosh TK. The duality of the inflammatory response to traumatic brain injury. Mol Neurobiol 2001;24(1-3):169-181

33 Hall ED, Yonkers PA, McCall JM, Braughler JM. Effects of the 21-aminosteroid U74006F on experimental head injury in mice. J Neurosurg 1988;68(3):456-461

34 Braughler JM, Pregenzer JF. The 21-aminosteroid inhibitors of lipid peroxidation: reactions with lipid peroxyl and phenoxy radicals. Free Radic Biol Med 1989;7(2):125-130

35 Clark WM, Hazel JS, Coull BM. Lazaroids. CNS pharmacology and current research. Drugs 1995;50(6):971-983

36 Hall ED, Braughler JM. Central nervous system trauma and stroke. II. Physiological and pharmacological evidence for involvement of oxygen radicals and lipid peroxidation. Free Radic Biol Med 1989;6(3):303-313

37 Ma J, Huang S, Qin S, You C. Progesterone for acute traumatic brain injury. Cochrane Database Syst Rev 2012;10:CD008409 